Note

\section{Evidence of a Urea-induced Sulfhydryl Oxidation Reaction in Proteins}

\author{
Youling L. Xıong and John E. Kinsella \\ Institute of Food Science, Cornell University, \\ Ithaca, NY 14853, U.S.A.
}

Received February 20, 1990

Urea is a denaturant and a solubilizing agent that is most widely used for the solubilization and unfolding of proteins by destabilizing the hydrogen bonding and hydrophobic interactions. ${ }^{1)}$ The destruction of intramolecular hydrogen bonds and hydrophobic interactions causes unfolding of component polypeptides and the transition from an ordered to a random coiled structure. This allows some previously buried functional groups, e.g., sulfhydryl (SH) of cysteine, to become exposed. The increased flexibility of protein molecules after unfolding may enhance the availability of some functional groups and facilitate their reactivity. Huggins et $a l^{21}$ and Frensdorff $e t a l .^{3)}$ have shown that bovine and human plasma albumin and egg ovalbumin, when at high concentrations, formed gels in concentrated urea. Sulfhydryldisulfide (SH-SS) interchange was implicated in the gelation process. However, the presumed SH-SS interchange products were not studied, and therefore, the role of urea in the polymerization of protein molecules was not fully explained. McKenzie and Ralston ${ }^{4)}$ reported that $\beta$-lactoglobulin formed polymers via intermolecular SH-SS interchange upon extensive incubation in concentrated urea. Because urea treatments for shorter periods are common for biological studies, information concerning the effect of urea on protein changes during the initial incubation period is needed.

In this study, the effect of urea on the exposure and oxidation of thiol groups and the formation of intermolecular disulfide linkages were continuously monitored by SH analyses and gel electrophoresis, using $\beta$-lactoglobulin $(\beta$ - $\mathrm{Lg})$ and bovine serum albumin (BSA) as model proteins.

$\beta$ - $\mathrm{Lg}$ ( 3 times crystallized and lyophilized) and BSA (98$99 \%$ albumin) powders were purchased from Sigma Chemical Co. (St. Louis, MO) and stored in a desiccator at $4{ }^{\circ} \mathrm{C}$ before use. Certified A.C.S. grade urea (containing $<0.0003 \%$ heavy metals and iron) was purchased from Fisher Scientific (Springfield, NJ), and electrophoreticgrade sodium dodecylsulfate (SDS) was obtained from Bio-Rad (Richmond, CA). Acrylamide, bis-acrylamide and $\beta$-mercaptoethanol were purchased from Sigma Chemical Co. (St. Louis, MO), and dithiobis(2-nitroben- zoic acid) (DTNB) was obtained from Aldrich Chemical Co. (Milwaukee, WI). All the other chemicals used in this study were of reagent grade. Water (solvent) was doubledistilled. $\beta$-Lg or BSA was solubilized in a $0.1 \mathrm{M}$ phosphate buffer ( $\mathrm{pH} 8.0$ ) before mixing with a concentrated (10.1 M) urea solution. The mixed protein-urea solution contained $4 \times 10^{-5} \mathrm{M}$ protein, $20 \mathrm{~mm}$ potassium phosphate at $\mathrm{pH} 8.0$, and 3.0 or $6.0 \mathrm{M}$ urea, and was incubated at $25^{\circ} \mathrm{C}$ for various periods prior to analyses. The free $\mathrm{SH}$ content of both the native and urea-incubated proteins was estimated in $6.0 \mathrm{M}$ urea and $10 \mathrm{~mm}$ potassium phosphate $(\mathrm{pH} 8.0)$, using DTNB, by the method of Ellman. ${ }^{5)}$ The increased absorbance of the protein solution after the addition of DTNB was monitored against a proper blank by using a Cary 219 double-beam spectrophotometer at $412 \mathrm{~nm}$ (Varian Assoc. Inc, Palo Alto, CA). The concentration of $\mathrm{SH}$ was estimated from the absorbance, using an extinction coefficient of $1.36 \times 10^{4} \mathrm{M}^{-1} \mathrm{~cm}^{-1}$. ) SDS-polyacrylamide gel electrophoresis (SDS-PAGE) was conducted according to the method of Laemmli ${ }^{6}$ using $3 \%$ (stacking) and $10 \%$ (resolving) polyacrylamide gels in miniature slab gel electrophoresis apparatus: (Hoefer Scientific Instrument, San Francisco, CA). Gels of $1.5 \mathrm{~mm}$ thickness were prepared, and $6 \mu \mathrm{g}$ of protein was loaded into each slot. The gels were fixed and stained in $50 \%$ methanol and $12 \%$ acetic acid containing $0.1 \%$ Coomassie brilliant blue R250, and destained in $18 \%$ ethanol and $8 \%$ acetic acid. A mixture of pure $\alpha$-lactalbumin (molecular weight 14,200$), \beta$-lactoglobulin $(18,300)$, bovine serum albumin $(66,300)$ and immunoglobulin $\mathrm{G}(\sim 160,000)$ was employed for protein standards to estimate the molecular weight of the protein bands.

The progressive changes in $\mathrm{SH}$ content of the proteins during the incubation with urea is exhibited in Fig. 1. Both

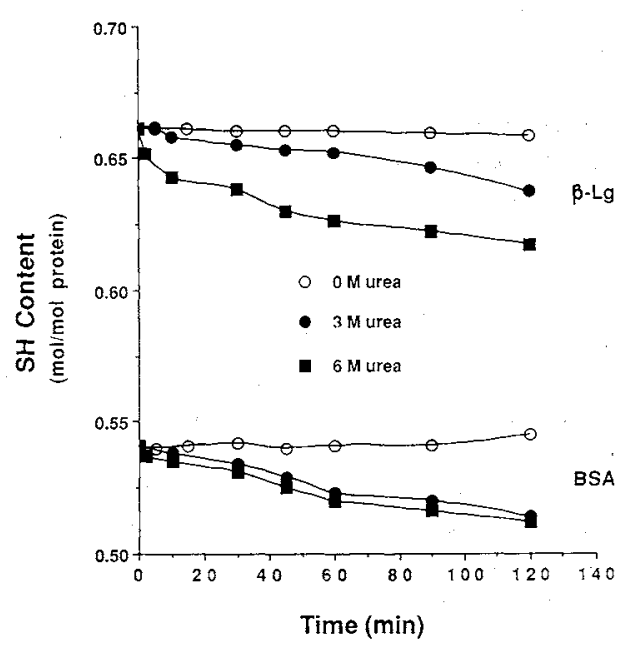

Fig. 1. Progressive Decrease in the Sulfhydryl (SH) Content of $\beta$-Lactoglobulin $(\beta$ - $\mathrm{Lg})$ and Bovine Serum Albumin (BSA) in the Presence of Urea with Incubation Time at $25^{\circ} \mathrm{C}$. 


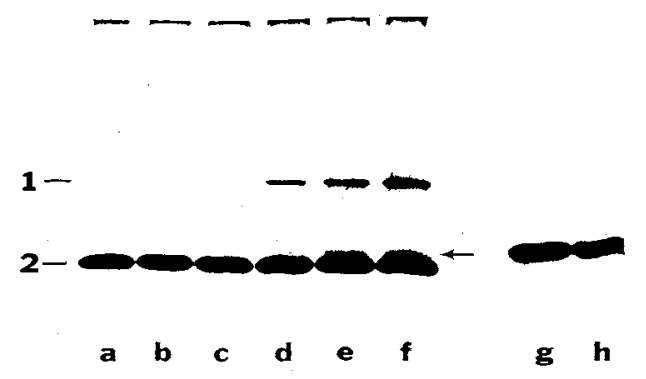

Fig. 2. Electrophoretic Patterns of Original $\beta$-Lactoglobulin ( $\beta$ - $\mathrm{Lg}$; Lanes a and $\mathrm{g})$ and $\beta$ - $\mathrm{Lg}$ Incubated in $6 \mathrm{M}$ Urea at $\mathrm{pH} 8.0$ and $25^{\circ} \mathrm{C}$ for 2 (b), 10 (c), 30 (d), 60 (e) and 120 (f and h) min.

Lanes a-f, without $\beta$-mercaptoethanol; lanes $\mathrm{g}$ and $\mathrm{h}$, with $5 \% \beta$-mercaptoethanol.

$\beta$ - $\mathrm{Lg}$ and BSA showed a decrease in SH content when urea was present, whereas in the absence of urea, the $\mathrm{SH}$ concentration was unchanged. This suggests that the disappearance of $\mathrm{SH}$, presumably via oxidation, was induced or facilitated by urea. The oxidation of $\mathrm{SH}$ was obvious in $3 \mathrm{M}$ urea, and was accelerated in $6 \mathrm{M}$ urea. As urea destabilized the hydrophobic interactions and hydrogen bonding, the native structure of both $\beta$ - $\mathrm{Lg}$ and BSA was altered, ") and apparently, this caused exposure of the SH groups, which were then oxidized.

Above $\mathrm{pH} 5.1, \beta-\mathrm{Lg}$ exists as a dimer. ${ }^{7)}$ In urea, the dimer dissociates into monomers, thereby exposing the free thiol group, which was originally occluded in the protein dimer. ${ }^{78)}$ In fact, the free SH of $\beta$-Lg was inaccessible to solvent at $\mathrm{pH} 8,{ }^{97}$ but it became exposed and reactive when the protein was dissociated by urea. The structure of BSA is more complex than that of $\beta$ - $\mathrm{Lg}$ since it contains 17 disulfide bonds and 1 thiol group. ${ }^{10)}$ The urea also facilitated SH oxidation in BSA. Both $\beta$ - $\mathrm{Lg}$ and BSA possess one free thiol group per molecule of protein, but a lower concentration of $\mathrm{SH}$ was observed with the samples used in this study. This may indicate that some of the thiol groups in the native proteins were already oxidized prior to use.

The oxidation of the thiol groups was accompanied by the appearance of new protein molecules. SDS-PAGE of $\beta$ - Lg showed a progressive formation of band 1 protein in the presence of $6 \mathrm{M}$ urea (Fig. 2, lanes a-f). This protein was presumably $\beta$-Lg dimer based on its mobility (molecular weight about 40,000). McKenzie and Ralston, ${ }^{4)}$ using column chromatography and relatively high protein concentrations $\left(5 \times 10^{-4} \mathrm{M}\right)$, detected the formation of the trimer and tetramer of $\beta-\mathrm{Lg}$ in $7 \mathrm{M}$ urea at $\mathrm{pH} 7.5$. When $\beta$ $\mathrm{Lg}$ was incubated without urea, the electrophoretic patterns were unchanged with the incubation time (results not shown). The content of the dimer was not prominent until after $30 \mathrm{~min}$ of incubation with urea. When $5 \% \beta$-mercaptoethanol was added to the SDS-PAGE samples, the

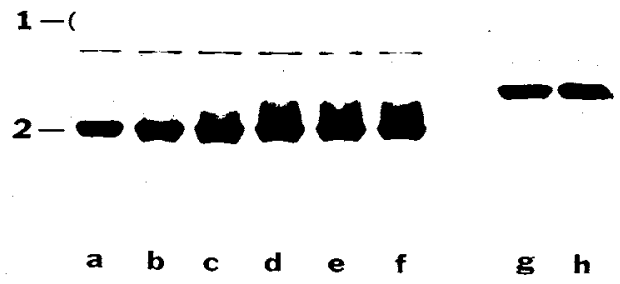

Fig. 3. Electrophoretic Patterns of Original Bovine Serum Albumin (BSA; Lanes a and g) and BSA Incubated in $6 \mathrm{M}$ Urea at $\mathrm{pH} 8.0$ and $25^{\circ} \mathrm{C}$ for 2 (b), 10 (c), 30 (d), 60 (e) and $120(\mathrm{f}$ and $\mathrm{h}$ ) $\mathrm{min}$.

Lanes a-f, without $\beta$-mercaptoethanol; lanes $g$ and $h$, with $5 \% \beta$-mercaptoethanol.

dimer disappeared (lanes $\mathrm{g}$ and $\mathrm{h}$ ), indicating that the formation of intermolecular disulfide bonds was responsible for the newly formed $\beta$ - $\mathrm{Lg}$ dimer. Furthermore, immediately above the monomeric $\beta-\mathrm{Lg}$ (band 2), a faint band gradually emerged (see the arrow in Fig. 2). This protein may have been an isomer of the original $\beta-\mathrm{Lg}$ formed after intramolecular SH-SS interchange which altered the protein structure. $\beta-\mathrm{Lg}$ was also incubated in a urea solution in the presence of $5 \mathrm{~mm}$ EDTA. The SDSPAGE patterns of the $\beta$-Lg products were identical to those obtained in the absence of any added chelating agent (results not shown). Hence, metallic ions were not involved in the urea-induced thiol oxidation and SH-SS interchange reactions observed in this study. Incidentally, the initial (urea-free) $\beta-\operatorname{Lg}$ (lane a) was already partly oxidized, since some polymers appeared which did not enter the gel (the band at the top of the ge1). When $\beta$-mercaptoethanol was added, the polymers disappeared (lane $\mathrm{g}$ ). Thus, the result is consistent with the low SH content in the initial protein sample (Fig. 1).

The original BSA monomer (band 2) gradually disappeared during incubation in $6 \mathrm{M}$ urea, and a smeared "band" above the monomer was concomitantly formed (Fig. 3, lanes a-f). Similar results were obtained when $5 \mathrm{~mm}$ EDTA was present in the protein-urea solution during incubation. This broad band may have included various isomeric forms of the original monomers with different structures produced by intramolecular SH-SS interchange reactions. Furthermore, the intensity of "band" 1 progressively increased during the incubation. The appearance of this wide band (band 1) corresponded to a diminution of the BSA monomer (band 2) and likely contained different BSA polymers. The 17 disulfides and the free SH in BSA could potentially allow the formation of various polymers via $\mathrm{SH}-\mathrm{SS}$ interchange. It is also evident that the protein did contain some impurities as manifested by some minor bands in the control sample (lane a), which may partially explain the low SH content observed in the control sample (Fig. 1). 
This study has shown that urea can facilitate SH oxidation and SH-SS interchange in proteins, and result in alteration of the proteins within a relatively short period of time, even in a dilute solution. Hence, it is important to control the urea-protein incubation conditions so that these $\mathrm{SH}$-involved reactions are minimized during the isolation or manipulation of proteins. This possibility of the urea effect may result in the formation of artifacts during protein isolation/solubilization studies.

Acknowledgment. This work was supported in part by the National Dairy Board.

\section{References}

1) S. Lapanje, "Physicochemical Aspects of Protein Denaturation," Wiley Interscience Publication, New York, 1978.
2) C. Huggins, D. F. Tapley and E. V. Jensen, Nature, 167, 592 (1951).

3) H. K. Frensdorff, M. T. Watson and W. Kauzmann, Am. Chem. Soc., 75, 5157 (1953).

4) H. A. McKenzie and G. B. Ralston, Aust. J. Biol. Sci., 26, 859 (1973).

5) G. L. Ellman, Arch. Biochem. Biophys., 82, 70 (1959).

6) U. K. Laemmli, Nature, 227, 680 (1970).

7) H. Pessen, J. M. Purcell and H. M. Farrell, Jr., Biochim. Biophys. Acta, 828, I (1985).

8) N. K. D. Kella and J. E. Kinsella, Int. J. Peptide Protein Res., 32, 396 (1988).

9) M. Z. Papiz, L. Sawyer, E. E. Eliopoulos, A. C. T. North, J. B. C. Findlay, R. Sivaprasadarao, T. A. Jones and M. E. Newcomer, Nature, 243, 383 (1986).

10) J. E. Kinsella and D. M. Whitehead, $A d v$. Food Res., 33, 343 (1989). 